\title{
Clinical and Radiological Assessment of Fluoroscopy Guided Injection of Atlantoaxial Joint in Rheumatoid Arthritis Patients
}

\author{
DOAA M. FOUAD, M.D. ${ }^{\mathbf{1}}$; SONYA M. RASHAD, M.D. ${ }^{2}$; MONA S. GAILY, M.D. ${ }^{2}$; \\ ABDELRAHEEM ELAWAMY, M.D. ${ }^{\mathbf{3}}$; MANAL HASSANIEN, M.D. ${ }^{\mathbf{4}}$ and NISREEN ADEL ABASS, M.D. \\ The Department of Radiology, South Egypt Cancer Institute, Assiut University ${ }^{\prime}$, \\ The Department of Rheumatology and Rehabilitation, Faculty of Medicine, Suez University ${ }^{2}$ \\ The Departments of Anesthesia, Intensive Care \& Pain Management ${ }^{3}$, Rheumatology \& Rehabilitation ${ }^{4}$ and Radiology $^{5}$ \\ Faculty of Medicine, Assiut University
}

\begin{abstract}
Background: Rheumatoid spondylitis is a feature of longlasting Rheumatoid Arthritis (RA), it presented by neck pain, headache and sleep disturbance. Atlantoaxial Joint (AAJ) is the commonest joint which affected among the cervical spine in patients with RA. When it is involved, it can be associated with dangerous complications.

Aim of Study: This study aimed to evaluate the efficacy of intra-articular steroid injection of inflamed AAJ in RA patients, on neck pain, headache and sleep quality as well as the pre and post injection MRI assessment.

Patients and Methods: Sixty rheumatoid arthritis patients with inflamed AAJ were recruited to the study. Group 1 (AAJ injected group, $n=30)$, received intraarticular atlantoaxial steroid injection, guided by fluoroscopy and Group 2 (control group, $\mathrm{n}=30$ ), received systemic steroids. Both groups were assessed with: Visual Analogue Scale (VAS) for nocturnal neck pain, Headache and Pittsburgh Sleep Quality Index (PSQI) for sleep disturbances. Contrast enhanced MRI before and after intervention were done for all patients.
\end{abstract}

Results: The injected AAJ group had significant improvement of nocturnal neck pain, headache and sleep disturbance during the three months' interval follow-up, in comparison to the control group. The injected AAJ group had a statistically significant improvement in the MRI synovial enhancement, inflammatory pannus, fibrosis and bone marrow edema in comparison to control group.

Conclusion: Intra-articular steroid injection of atlantoaxial joint is considered as an efficient therapeutic option in acute inflamed atlantoaxial joint of RA patients regarding clinical and radiological findings.

Key Words: Rheumatoid arthritis - Intra-articular injection - Steroid - MRI findings - Inflammatory rheumatoid spondylitis.

Correspondence to: Dr. Doaa M. Fouad, The Department of Radiology, South Egypt Cancer Institute, Assiut University

\section{Introduction}

RHEUMATOID arthritis is a common type of autoimmune arthritis which is characterized by inflammation of the synovial membranes. Cervical spine involvement is a feature of long-lasting disease, where atlantoaxial impaction with vertical subluxation of the odontoid process through the foramen magnum being one of the greatest and dangerous complications [1]

The early complains of rheumatoid spondylitis are cranio-cervical neck pain, occipital headache and sleep disturbance. Later on especially, if the disease is not controlled, complications could be motor weakness, decreased endurance, gait difficulty, paresthesia of the hands, loss of fine dexterity and may progress to incontinence [2-4].

Vertebro-basilar insufficiency may appear mainly in patients with atlantoaxial instability where the patients complains of vertigo, loss of equilibrium, visual disturbances, tinnitus, and dysphagia $[5,6]$.

Magnetic Resonance Imaging (MRI) can be used for assessment of the disease activity in term

\footnotetext{
List of Abbreviations:

RA : Rheumatoid Arthritis.

AAJ : Atlantoaxial Joint.

ACR : American College of Rheumatology.

MRI : Magnetic Resonance Imaging.

STIR : Short Time Inversion Recovery.

AAI : Atlantoaxial Instability.

DAS : Disease Activity Score.

PSQI : Pittsburgh Sleep Quality Index.

VAS : Visual Analogue Scale.

NDI : Neck Disability Index.
} 
of synovial inflammation, pannus formation and bone marrow edema as well as any associated cervical myelopathy in severe cases [7].

Early aggressive medical treatment may be needed in many cases to control rheumatoid Atlantoaxial Joint (AAJ) pain. Intra-articular steroids had been proved to be a safe and effective therapy producing pain relief lasting for nearly one year $[8,9]$. Recent studies have approved the efficacy of intra-articular steroids injection of the AAJ on neck pain and disability $[\mathbf{1 0 , 1 1 ]}$.

The current study aimed at assessing the efficacy of intra-articular steroid injection in RA patients with inflamed Atlantoaxial Joint (AAJ).

\section{Patients and Methods}

The current study is a prospective (case-control) study, was conducted from November 2018 to November 2019. The study was approved from the Ethical Committee of Faculty of Medicine, Assiut University, after obtaining a written and an informed consent from each participant.

Inclusion criteria were patients fulfilling the American College of Rheumatology (ACR) (2010) criteria for RA [12]. All the recruited patients underwent clinical assessment to detect the clinical activity of the disease using Rheumatoid disease activity score DAS28, patients should have a score less than 2.6 for at least 3 months prior to enrollment to the study. They were suffering from nocturnal upper neck pain and/or headache due to inflamed Atlantoaxial Joint (AAJ) and scored according to Visual Analogue Scale (VAS), five or more. They had evidence of acute inflammation of AAJ (bone marrow edema, synovial enhancement and/or pannus) in MRI study. Laboratory finding of C-reactive protein of $12 \mathrm{mg} / \mathrm{L}$ or more was detected as well.

Exclusion criteria were active RA (DAS >2.6), neck pain due to other pathology such as disc herniation, cervical spondylosis, fibromyalgia, pregnancy and untreated coagulopathy. History of allergy to iodinated dye is also a cause of exclusion.

The included patients were randomly assigned to one of the two studied groups through a webbased randomizer, as the following; Group 1 (injected AAJ group, $n=30$ ), received AAJ injection with $1.0 \mathrm{ml}$ of a mixture of $0.5 \mathrm{ml}$ of bupivacaine $0.5 \%$ and $0.5 \mathrm{ml}, 20 \mathrm{mg}$ of triamcinolone acetate, and Group 2 (control group, $\mathrm{n}=30$ ), received systemic steroids; oral prednisolone tablet, $15 \mathrm{mg} /$ day for two weeks. Both groups were receiving $12.5 \mathrm{mg}$ methotrexate per week and chloroquine 400mg per day.

\section{Magnetic resonance imaging procedure:}

Magnetic Resonance Imaging (MRI) of the cervical spine was requested for all patients' pre and post intervention assessment. The first MRI study was done before inclusion in the study to detect inflammatory acute findings. While the second study was done after three months' interval, as a follow-up. MRI was done using a 1.5 Tesla scanner (Acheiva, Philips, Netherlands). The patients were positioned supine with a neck coil around the neck in neutral position. Special emphasis was made on the sequences of sagittal T2weighted fast spin-echo (TR/TE: 2880-3000/120 msec., slice thickness/slice gap: $3 / 0.3 \mathrm{~mm}$ ) and STIR (short time inversion recovery) images (TR/TE: 3.

2800-3200/70-120msec., slice thickness/slice gap: $4 / 0.6 \mathrm{~mm}$ ) as well as pre and post-contrast injection images of sagittal and axial T1-weighted fast spin-echo (TR/TE: 400-430/8msec., slice thickness/slice gap: $3 / 0.3 \mathrm{~mm}$ ), post-contrast images were obtained 5 minutes after injection. The sagittal images were obtained with a field of view of 160 X 251 X 50mm and reconstruction matrix of 512 $X$ 512. The axial images were obtained with a field of view of $170 \times 170 \times 66 \mathrm{~mm}$ and reconstruction matrix of $352 \times 352$.

\section{Pre-intervention assessment:}

The two groups were initially assessed for nocturnal neck pain by Visual Analogue Scale (VAS). Patients recorded pain intensity on $100 \mathrm{~mm}$ VAS by drawing a vertical line on the horizontally positioned scale where $0=$ 'no pain' and $10=$ 'most severe pain imaginable'.

Headache was evaluated using VAS where patients recorded headache on 100-mm VAS, $0=$ 'no headache' and 100='most severe headache imaginable'.

Sleep disturbance, was scored according to Pittsburgh Sleep Quality Index (PSQI) score. PSQI is a self-rated questionnaire which assesses sleep quality and disturbances over a 1-month time interval. It consists of nineteen items which generate seven "component" scores: Subjective sleep quality, sleep latency, sleep duration, habitual sleep efficiency, sleep disturbances, use of sleeping medication, and daytime dysfunction. Each component is weighted on a 0-3 interval scale. The global PSQI score is then calculated by totaling the seven component scores, providing an overall score rang- 
ing from 0 to 21 , where lower scores denote a better sleep quality [13].

\section{Atlantoaxial joint steroid injection procedure:}

Patients were placed in a prone position with a pillow under the chest to allow slight neck flexion. The upper neck is sterilized and draped. The Carm is brought to the head of the patient and anteroposterior image was obtained. Then the $\mathrm{C}$-arm is rotated in a cephalo-caudal direction to obtain the best view for the lateral AAJ. The needle insertion site was marked on the skin overlying the lateral third of the AAJ. A skin wheel is raised with $2 \mathrm{ml}$ of xylocaine $1 \%$ at the insertion site. Then, a 22 Gauge, three and half inches' blunt needle was advanced towards the posterolateral aspect of the inferior margin of the inferior articular process of the atlas $(\mathrm{C} 1)$ vertebra. At that point, a lateral view was obtained. The needle was withdrawn slightly, directed towards the joint line of the (AAJ), and advanced just for 2 millimeters. Usually a distinctive pop is felt indicating entry to the joint cavity. After careful negative aspiration for blood or cerebrospinal fluid, $0.2 \mathrm{ml}$ of Omnipaque dye was injected to verify intra-articular placement of the tip of the needle under direct real-time fluoroscopy to check for inadvertent intra-arterial injection. Anteroposterior and lateral views were obtained to ensure that the contrast agent remained confined to the joint cavity without escape to the surrounding structures. Finally, $1.0 \mathrm{ml}$ of a mixture of $0.5 \mathrm{ml}$ of bupivacaine $0.5 \%$ and $0.5 \mathrm{ml}$, "20mg" of triamcinolone was injected, as shown in Fig. (1) [14]. The same procedure was repeated for the other side.
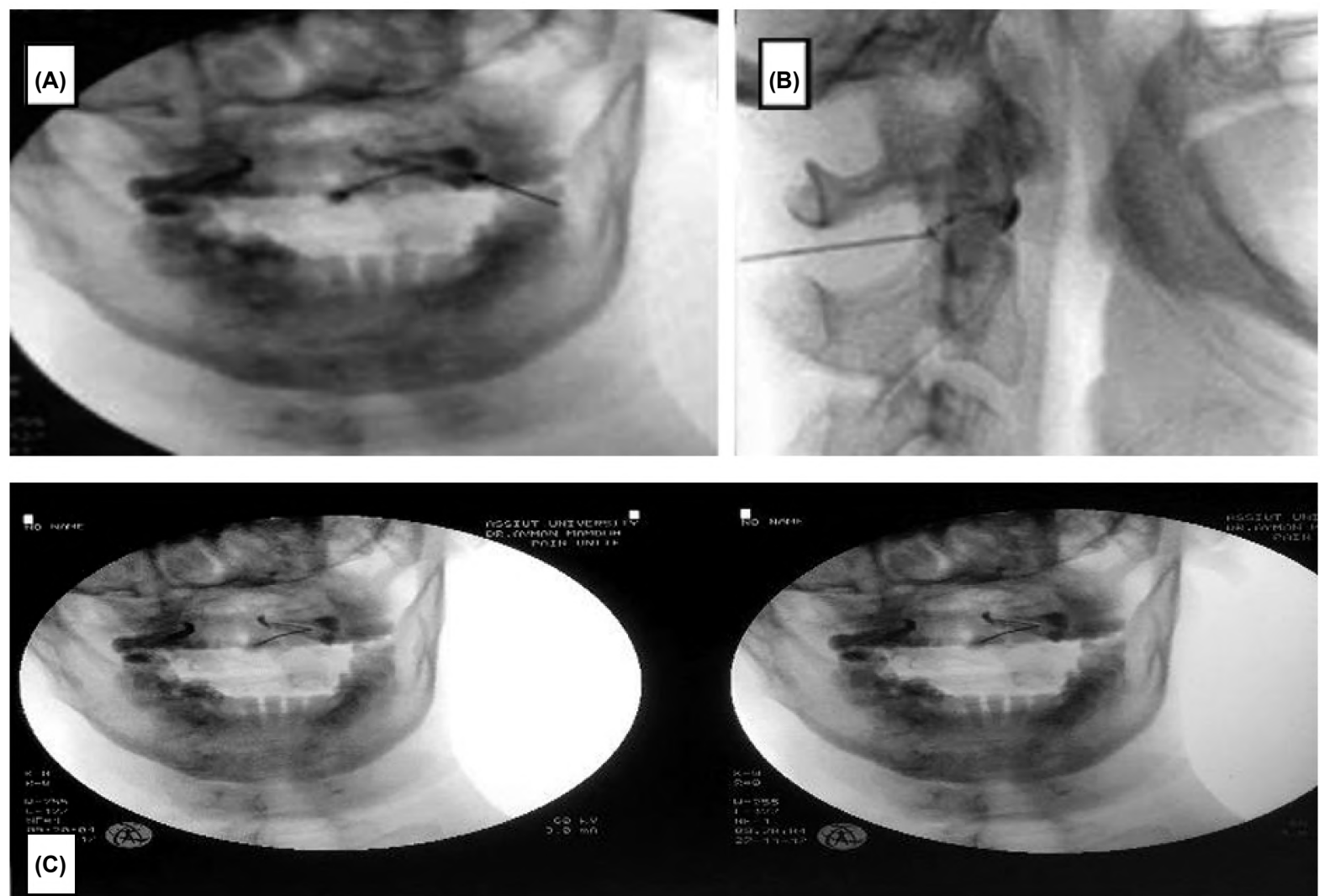

Fig. (1): (A, B, C): Illustrated fluoroscopic images shows the radiological landmarks of AA joint and the needle entry direction. (A) Antero-posterior, (B) Lateral view): $22 \mathrm{G} 3$ ? inch is advanced towards the posterolateral aspect of inferior margin of the inferior articular process of $\mathrm{C} 1$, then needle withdrawn slightly, directed toward the joint line of AAJ. (C) Fluoroscopy monitor with cases blunt needle are advanced toward injection sites.

\section{Post-intervention assessment:}

The two groups were then followed-up every 2 weeks for 3 months by clinical scores. MRI parameters were reassessed three-month post intervention.

\section{Results}

Baseline demographic, clinical and imaging characteristics: Thirty RA patients with MRI findings of AAJ inflammation underwent intra-articular AAJ steroid injection. Thirty matched RA patients 
were included as a control group. There were no statistically significant differences between two groups in patient demographics, clinical and imaging characteristics (Table 1).

Table (1): Baseline demographic, clinical and imaging characteristics of the studied groups $(n=60)$.

\begin{tabular}{lllc}
\hline Characteristics & $\begin{array}{c}\text { AAJ Inj group } \\
\text { No. 30 }\end{array}$ & $\begin{array}{c}\text { Control group } \\
\text { No. 30 }\end{array}$ & $\begin{array}{c}p \text { - } \\
\text { value* }\end{array}$ \\
\hline Age [years, mean \pm SD] & $40.2 \pm 11.3$ & $40.8 \pm 11.6$ & 0.82 \\
Gender [female, n (\%)] & $27(90 \%)$ & $27(90 \%)$ & \\
Disease duration [years, mean $\pm \mathrm{SD}$ ] & $8.3 \pm 4.6$ & $7.2 \pm 5.1$ & 0.18 \\
Nocturnal pain [mean \pm SD] & $60.3 \pm 17.1$ & $58.5 \pm 17.9$ & 0.71 \\
Severity of headache on VAS [mean $\pm \mathrm{SD}$ ] & $60.7 \pm 17.6$ & $56.5 . \pm 18.8$ & 0.41 \\
NDI [mean \pm SD] & $36.7 \pm 8.7$ & $35.1 \pm 7.1$ & 0.46 \\
Sleep disturbance [present, n (\%)] & $20(66.7 \%)$ & $22(73.3 \%)$ & 0.56 \\
Pittsburgh sleep quality index score [mean $\pm \mathrm{SD}$ ] & $10.5 \pm 5.1$ & $11.7 \pm 3.7$ & 0.42 \\
MRI synovial enhancement [present, $(\%)$ ] & $20(66.7 \%)$ & $21(70 \%)$ & 0.67 \\
MRI bone marrow edema [present, $\mathrm{n}(\%)]$ & $30(100 \%)$ & $30(100 \%)$ & \\
MRI sub-axial joint affection [present, $\mathrm{n}(\%)]$ & $13(43.3 \%)$ & $11(36.7 \%)$ & 0.58 \\
\hline
\end{tabular}

Data are presented as mean $\pm \mathrm{SD}$, numbers and percentages.

$*: p<0.05$ is considered statistically significant.

The procedural and post procedural adverse effects are summarized in (Table 2). All procedural side effects were resolved and no long-term patient sequelae were identified. All post-procedural side effects resolved within the first month without further medical intervention, and no long-term sequelae were identified.

Table (2): Procedural and post-procedural side effects $(\mathrm{N}=30$ injections).

\begin{tabular}{ll}
\hline Type of adverse event & $\begin{array}{c}\text { Frequency } \\
(\mathrm{n}, \%)\end{array}$ \\
\hline Overall side effects & $6(20 \%)$ \\
Procedural: & $3(10 \%)$ \\
Vascular contrast uptake & $1(3.3 \%)$ \\
Paresthesia & $0(0.0 \%)$ \\
Vasovagal response & $1(3.3 \%)$ \\
Blood return & $0(0.0 \%)$ \\
Increased pain & $1(3.3 \%)$ \\
Extravasation of contrast & $0(0.0 \%)$ \\
Seizure & $0(0.0 \%)$ \\
Post -procedural: & $3(10 \%)$ \\
Increased pain & $1(3.3 \%)$ \\
Neurological change & $0(0.0 \%)$ \\
Vertigo/balance difficulty/dizziness & $1(3.3 \%)$ \\
Paresthesia & $0(0.0 \%)$ \\
Flushing sensation & $1(3.3 \%)$ \\
Infection & $0(0.0 \%)$ \\
Bleed/bruise/surgical care needed & $0(0.0 \%)$ \\
\hline
\end{tabular}

Data are presented as mean \pm SD.

$*: p<0.05$ is considered statistically significant.

\section{Post intervention outcomes:}

The percentage of patients who had sleep disturbance at baseline was $66.7 \%$ and $73.3 \%$ in injected AAJ and control groups respectively which had significantly decreased to $6.7 \%$ and $43.3 \%$ after three months (Table 3). Table (4) shows the results of PSQI score at baseline and three months' post-intervention in studied groups.

Table (3): Sleep disturbances in injected AAJ and control group $(n=60)$.

\begin{tabular}{llll}
\hline Sleep disturbance & $\begin{array}{c}\text { AAJ inj. group } \\
\text { No. 30 }\end{array}$ & $\begin{array}{c}\text { Control group } \\
\text { No. 30 }\end{array}$ & $\begin{array}{c}p^{-} \\
\text {value* }\end{array}$ \\
\hline $\begin{array}{l}\text { - Pre-intervention } \\
\text { - Three months post }\end{array}$ & $20(66.7 \%)$ & $22(73.3 \%)$ & 0.56 \\
$\begin{array}{l}\text { intervention } \\
\text { - } p \text {-value* }\end{array}$ & $0.004 *$ & $13(43.3 \%)$ & $0.039 *$ \\
\hline
\end{tabular}

Data are presented as numbers and percentages.

*: $p<0.05$ is considered statistically significant.

Table (4): Pittsburgh sleep quality index score of injected AAJ and control groups $(n=60)$.

\begin{tabular}{lccl}
\hline $\begin{array}{l}\text { Pittsburgh sleep } \\
\text { quality index score }\end{array}$ & $\begin{array}{c}\text { AAJ inj. group } \\
\text { No. 30 }\end{array}$ & $\begin{array}{c}\text { Control group } \\
\text { No. 30 }\end{array}$ & $\begin{array}{c}p \text { - } \\
\text { value* }\end{array}$ \\
\hline - Pre-intervention & $10.5 \pm 5.1$ & $11.7 \pm 3.7$ & 0.42 \\
- Three months post & $4.43 \pm 3.27$ & $9.54 \pm 5.94$ & $<0.001 *$ \\
intervention & $0.024^{*}$ & 0.64 & \\
• $p$-value* & & \\
\hline $\begin{array}{l}\text { Data are presented as mean } \pm \text { SD. } \\
*: p<0.05 \text { is considered statistically significant. }\end{array}$
\end{tabular}

Headache severity had significantly decreased in injected AAJ group during the follow-up in comparison to the control group (Table 5).

Table (5): Severity of headache follow-up post intervention in injected AAJ and control groups $(n=60)$.

\begin{tabular}{llll}
\hline $\begin{array}{l}\text { Headache } \\
\text { by VAS }\end{array}$ & $\begin{array}{c}\text { AAJ inj. group } \\
\text { No. } 30\end{array}$ & $\begin{array}{c}\text { Control group } \\
\text { No. } 30\end{array}$ & $\begin{array}{c}p \text { - } \\
\text { value* }\end{array}$ \\
\hline Two weeks & $22.68 \pm 16.74$ & $45.17 \pm 15.83$ & $<0.001 *$ \\
Four Weeks & $14.21 \pm 5.66$ & $45.69 \pm 11.96$ & $<0.001 *$ \\
Six weeks & $6.87 \pm 4.76$ & $48.36 \pm 10.65$ & $<0.001 *$ \\
Eight weeks & $7.11 \pm 3.99$ & $50.83 \pm 9.85$ & $<0.001 *$ \\
Twelve weeks & $7.54 \pm 5.23$ & $48.52 \pm 11.98$ & $<0.001 *$ \\
\hline
\end{tabular}

Data are presented as mean $\pm \mathrm{SD}$

*: $p<0.05$ is considered statistically significant. 
The pre-intervention nocturnal pain score was $60.3 \pm 17.1$ in injected AAJ group and $58.5 \pm 17.9$ in control group. Pain had significantly decreased after two weeks in injected AAJ group with continuous improvement till 3 months' postintervention. Different nocturnal pain scores at two, four, eight and twelve weeks in both groups is presented in (Table 6). There was significant difference between the two groups along the different follow-up visits $(p<0.001)$.

Regarding the MRI imaging findings, there were no significant differences concerning MRI synovial, pannus enhancement, bone marrow edema and sub-axial joint affection at baseline evaluation. After three months AAJ injection group showed statistically significant decrease in the percentage of patients with persistent MRI findings in comparison to control group (Table 7) Figs. (2-6).

Table (6): Nocturnal pain follow-up post intervention in injected AAJ and control groups.

\begin{tabular}{lccc}
\hline $\begin{array}{l}\text { Nocturnal pain } \\
\text { by VAS }\end{array}$ & $\begin{array}{c}\text { AAJ inj. group } \\
\text { No. 30 }\end{array}$ & $\begin{array}{c}\text { Control group } \\
\text { No. 30 }\end{array}$ & $\begin{array}{c}p \text { - } \\
\text { value* }\end{array}$ \\
\hline Two weeks & $15.2 \pm 7.8$ & $50.83 \pm 11.9$ & $<0.001 *$ \\
Four Weeks & $9.13 \pm 4.6$ & $52.50 \pm 9.58$ & $<0.001 *$ \\
Six weeks & $7.2 \pm 3.96$ & $50.21 \pm 18.80$ & $<0.001 *$ \\
Eight weeks & $6.5 \pm 5.21$ & $48.5 \pm 12.65$ & $<0.001 *$ \\
Twelve weeks & $6.9 \pm 4.65$ & $51.26 \pm 10.54$ & $<0.001 *$ \\
\hline
\end{tabular}

Data are presented as mean $\pm \mathrm{SD}$

*: $p<0.05$ is considered statistically significant

Table (7): Imaging findings three months' post-intervention in injected AAJ and control groups.

\begin{tabular}{llll}
\hline Radiographic findings & $\begin{array}{c}\text { AAJ inj. group } \\
\text { No. 30 }\end{array}$ & $\begin{array}{c}\text { Control group } \\
\text { No. 30 }\end{array}$ & $\begin{array}{c}p \text { - } \\
\text { value* }\end{array}$ \\
\hline MRI pannus and synovial enhancement [present, n (\%)] & $7(23.3 \%)$ & $19(63.3 \%)$ & $<0.002^{*}$ \\
MRI bone marrow edema [present, $\mathrm{n}(\%)]$ & $4(13.3 \%)$ & $12(40 \%)$ & $<0.002^{*}$ \\
MRI sub-axial joint affection [present, $\mathrm{n}(\%)]$ & $12(40 \%)$ & $11(36.7 \%)$ & 0.58 \\
\hline
\end{tabular}

Data are presented as numbers and percentages.

*: $p<0.05$ is considered statistically significant.

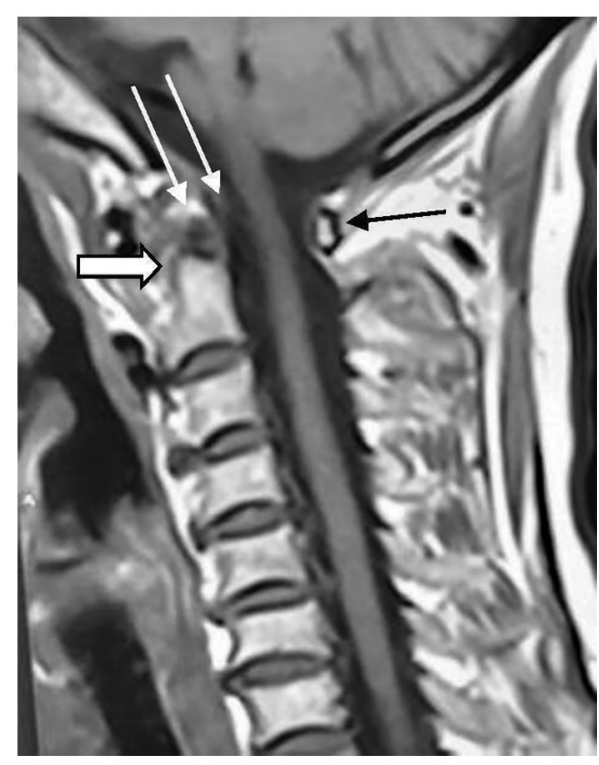

(A)

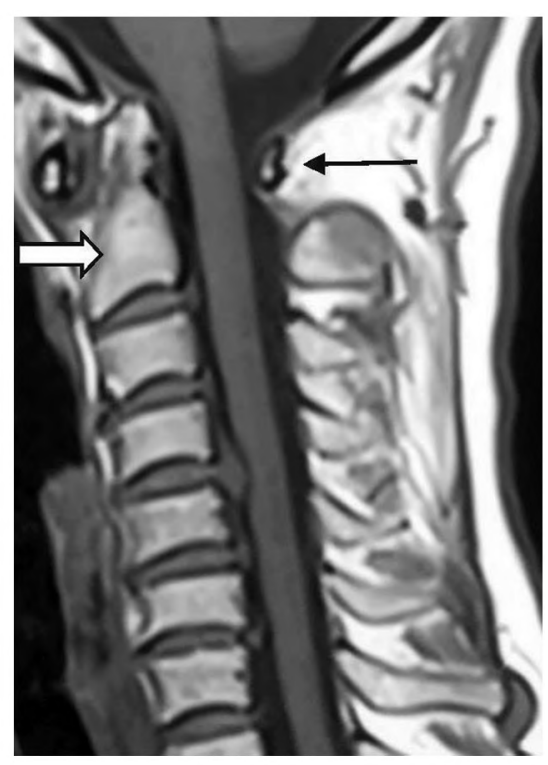

(B)

Fig. (2): 35 years old female patient. Post contrast sagittal T1WI. (A) Pre-injection) revealed: Large enhanced synovial and pannus formation (long white arrows) which slightly encroaches the epidural space toward the spinal cord. The black arrows show anterior displacement of the posterior arch of Atlas C1 toward the cord. And hyper intense signal of bone edema (block white arrow). (B) Post injection) revealed: Decrease of the inflammatory pannus enhancement, size and encroachment upon the cord. Noted significant improvement of the anterior protrusion of the atlas toward the cord as well as bone edema. 
(A)
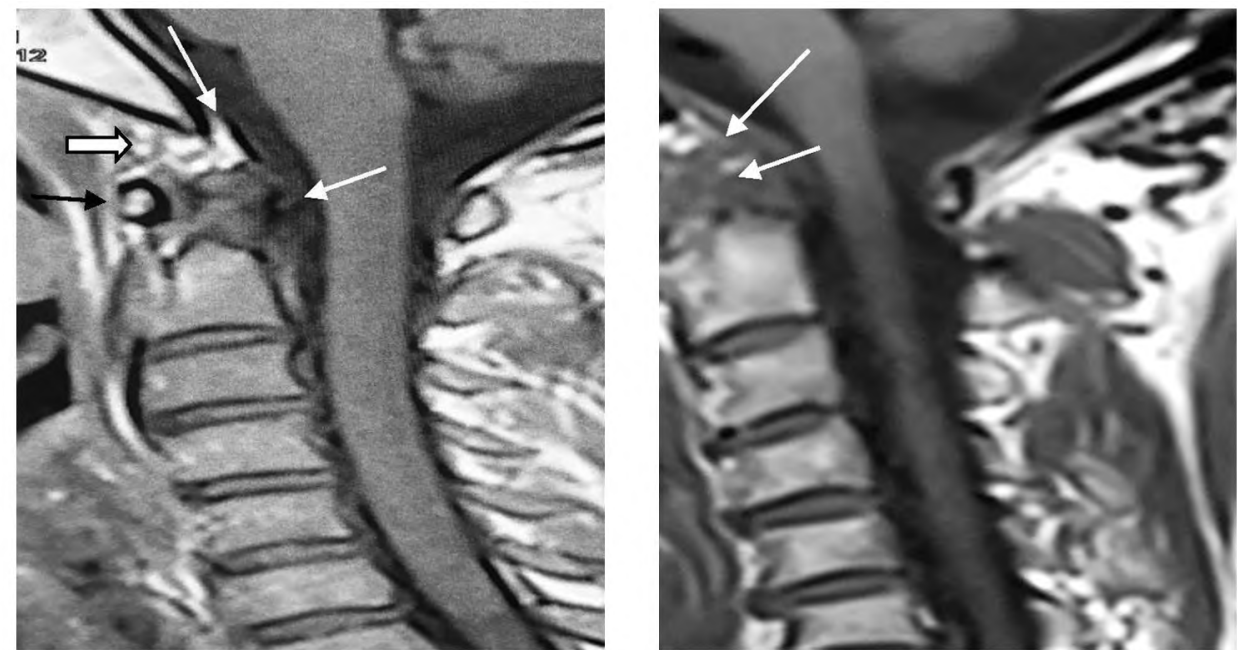

(B)

Fig. (3): (A) 55 years old female patient. Post contrast sagittal T1WI, (A: Pre-injection) and (B: Post-injection) of atlantoaxial joint (A: Shows marked inflammatory pannus seen around the dens, encroaches the CSF space and touching the spinal cord (white arrows) with near complete effacement of the CSF space in front of it, noted small areas of mild enhancement at the pannus formation (black arrows). Noted small areas of joint effusion (white block arrow).(B: Shows mild decrease in both size and enhancement of the inflammatory pannus with relief of the cord compression and the CSF space.

(A)
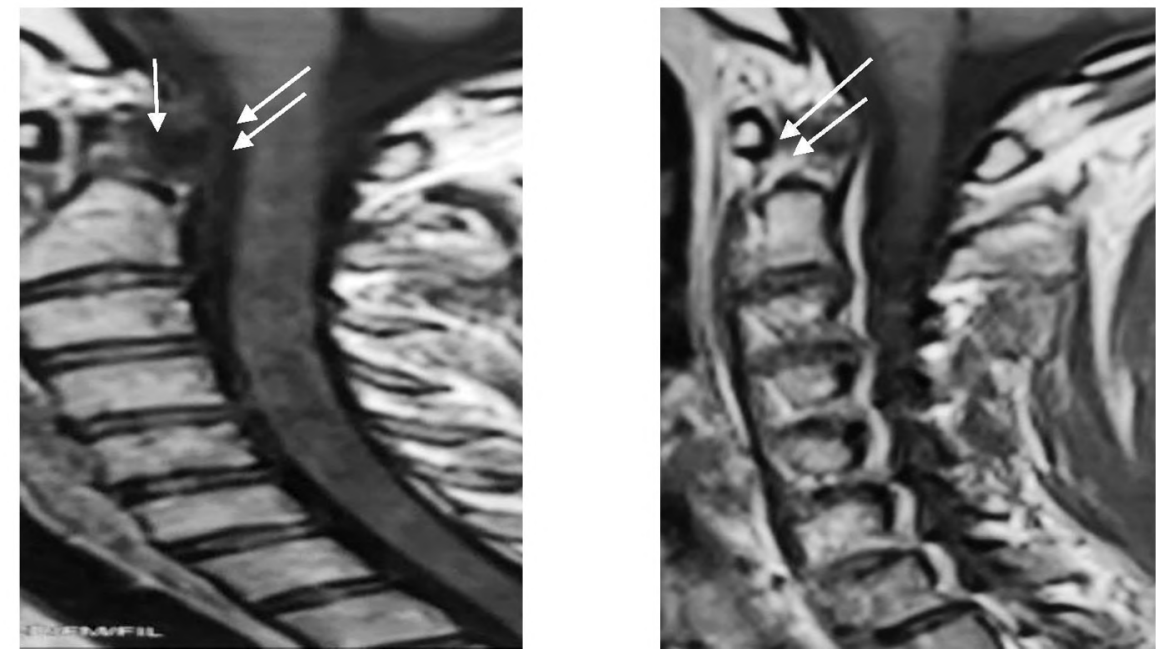

(B)

Fig. (4): 34 years' female patient. Post contrast sagittal T1WI (A: Pre-injection) and (B: Post-injection) of atlantoaxial joint. (A) Shows circumferential inflammatory thickening around the dense (show subtle enhancement), and around the arch of $\mathrm{C} 1$ at right most lateral cuts (white arrows). (B) Shows mild decrease in both size and enhancement of the circumferential thickening.
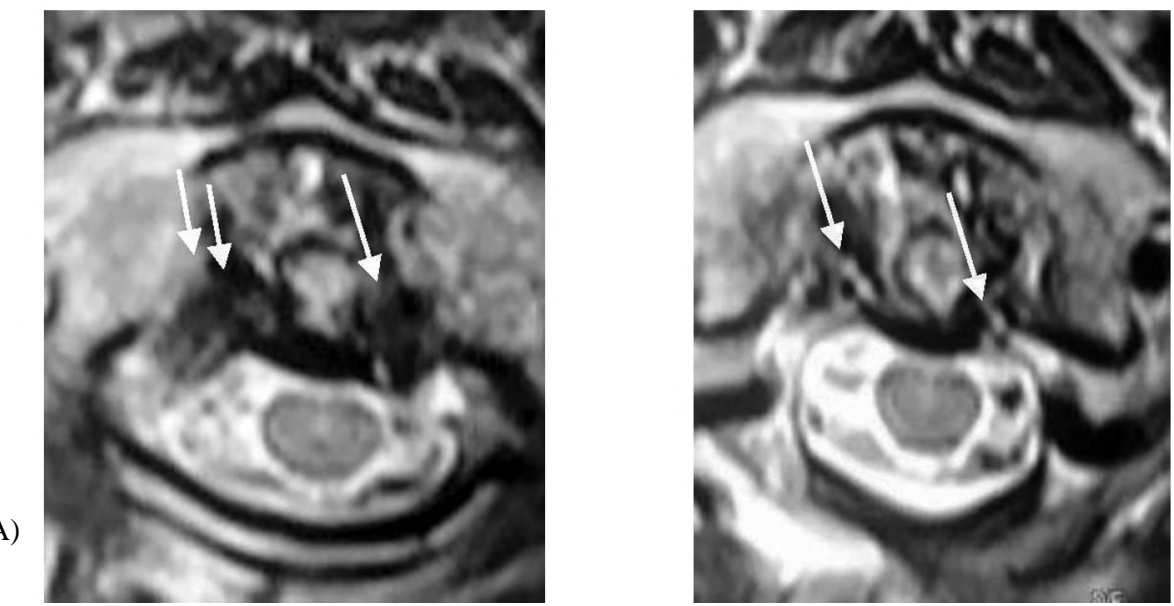

Fig. (5): Post contrast axial T1 WI, (A: Pre-injection) and (B: Post- injection) of atlantoaxial joint 60 years' rheumatoid arthritis female patient. (A) Show areas of inflammatory and pannus formation encroach upon the SCF space more to the left side. (B) Significant improvement of previous noted inflammatory pannus (short arrows). 
(A)
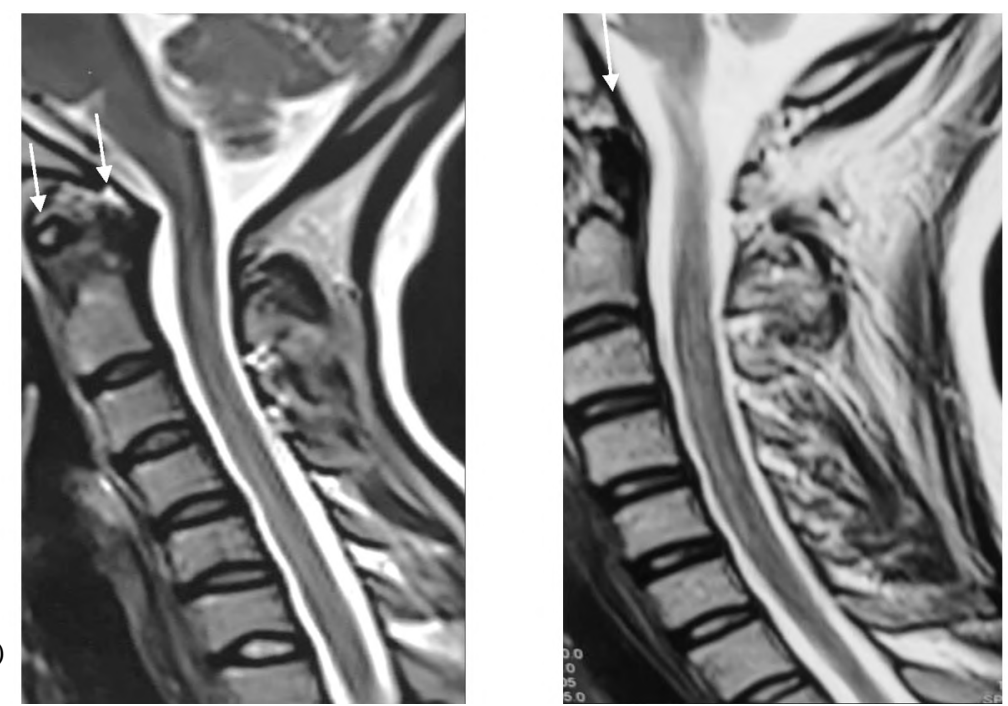

(B)

Fig. (6): Sagitta MRI T2w. (A: Pre- injection) and (B: Post injection). A: Noted large area of inflammatory pannus with small areas of enhancement inside and posterior protrusion of the dense by the inflammation toward the cord with encroachment of the CSF space. B: Show decrease of the posterior protrusion of the inflammatory dens toward the cord.

\section{Discussion}

Rheumatoid Arthritis (RA) is a chronic systemic inflammatory disease that primarily affects bones, synovial joints, and ligaments $[\mathbf{1 5 , 1 6 ]}$. While the most prominent joints affected in RA affection are the small peripheral joints, the second most commonly involved region is the cervical spine [15-18] The prevalence of cervical spine involvement in RA ranges from $25 \%$ to $80 \%$, depending on the used diagnostic criteria $[\mathbf{1 5 , 1 6 , 1 9 ]}$. One of the earliest indicators of cervical spine involvement in RA is neck pain, where 40 to $88 \%$ of RA patients report complaints of this symptom [15]. Another important issue with RA is sleep disturbance where patients often report problems with poor sleep quality, issues with falling asleep, as well as headache after sleep [20]

Recent studies suggest that up to $80 \%$ of patients with RA have radiographic cervical spine involvement some of them appear as early as within 2 years of initial diagnosis with RA [21]. Because of the severe and potentially deadly complications of cervical spine disease in RA, its early diagnosis and treatment should be a priority in patients with RA. Intra-articular steroid injection had been thoroughly studied in RA with peripheral arthritis; however, this assessment didn't extend for cervical region involvement. AS the effectiveness of AAJ injection on other clinical findings of inflamed AAJ is not measured yet. Accordingly, the current study aimed at assessing the efficacy of intraarticular steroid injection of inflamed atlantoaxial joint, guided by fluoroscopy, on nocturnal neck pain, headache and sleep quality, using pre and post injection MRI in RA patients.

In current study, $30 \mathrm{RA}$ patients underwent lateral AAJ intra-articular local anesthetic and steroid injection. The overall prevalence of injection adverse effects in this study was $20 \%$. The most common procedural adverse effects were vascular contrast uptake, vasovagal response and increased pain the most common post-procedural adverse effects were increased pain, vertigo/dizziness and flushing sensation. These findings are similar that of Aiudi et al., where they reported an overall prevalence of adverse effects of $18.5 \%$. The most common procedural adverse effect was vascular uptake of contrast and the most common postprocedural adverse effect was increased pain [21,22]

We reported a decrease in the number of patients complained of sleep disturbance from 20 to 2 patients after 3 months following AAJ injection. In addition, the mean Pittsburgh Sleep Quality Index Score (PSQI) had dropped from 10.5 to 4.43 at three months' post-intervention.

In the current study, the mean pain scores decreased from 60.3 at baseline to 6.9 at three months. While mean headache score dropped from 60.7 to 7.54 at three months. In a research assessing the effect of AAJ injection in patients with crevicogenic headache, 15 patients showed complete abolition of the headache after AAJ injection and the mean pain scores dropped from a baseline of 6.8 
to 3.6 at 3 months. These findings suggest that intra-articular steroid injection is effective in relief of pain and headache originating from AAJ.

Finally, MRI findings also showed obvious improvement after AAJ injection, changes are more evident regards the pannus formation, synovial enhancement and bone edema. There were persistent inflammatory findings and pannus formation in $23.3 \%$ and $63.3 \%$ for the AAJ injection group versus control group at three months' interval. While bone marrow edema was persistent in $13.3 \%$ and $40 \%$ for 11 injection versus control group respectively. However, there was no significant changes of sub-axial joint affection among the two groups. These findings were convergent to Hetta., et al., and other authors [10-11] who reported that synovial enhancement improved significantly in injection group compared to control group by ( $72.7 \%$ vs. $43.5 \%, p=0.026)$ while current study revealed $(76.6 \%$ vs. $36.7 \%, p=0.008)$ respectively. While for improvement of bone marrow edema they reported $(71.4 \%$ vs. $42.9 \% ; p=0.033)$ which were close to our results $(86.5 \%$ and $60 \%, p=0.008)$ for the AAJ injection group compared with control group. The relatively high improvement rates in current study may have attributed to the fact that some cases had additional doses of steroids (for both the injection and oral groups) as a plane of treatment for other symptoms which consequently improve their MRI findings as well.

\section{Conclusion:}

Intra-articular steroid injection of inflamed atlantoaxial joints in rheumatoid arthritis patients is considered as a significant therapeutic option regarding both clinical symptoms and radiological findings.

\section{References}

1- ROTARU N., CRIVCEANSCHII M., CONDREA E., SEU V. and CODREANU I.: Temporomandibular Joint Deformities and Atlantoaxial Impaction in Rheumatoid Arthritis. J. Case Rep. Clin. Med., 1 (1): 111, 2017.

2- FUJIWARA K., YONENOBU K. and OCHI T.: Natural history of upper cervical lesions in rheumatoid arthritis. J. Spinal Disord., Aug., 10 (4): 275-81. [Medline], 1997.

3- PAIMELA L., LAASONEN L. and KANKAANPAA E. Progression of cervical spine changes in patients with early rheumatoid arthritis. J. Rheumatol., Jul. 24 (7): 1280-4. [Medline], 1997.

4- PELLICCI P.M., RANAWAT C.S., TSAIRIS P. and BRYAN J.: A prospective study of the progression of rheumatoid arthritis of the cervical spine. J. Bone Joint Surg. Am., Mar., 63 (3): 342-50. [Medline], 1981.

5- TANIGUCHI D., TOKUNAGA D., HASE H., et al.: Evaluation of lateral instability of the atlanto-axial joint in rheumatoid arthritis using dynamic open-mouth view radiographs. Clin. Rheumatol., Jul., 27 (7): 851-7. [Medline], 2008.

6- MORIZONO Y., SAKOU T. and KAWAIDA H.: Upper cervical involvement in rheumatoid arthritis. Spine, Oct. 12 (8): 721-5. [Medline], 1987.

7- SCUTELLARI P.N. and ORZINCOLO C.: Rheumatoid arthritis: Sequences. Eur. J. Radiol., 27: S31-38, 1998.

8- NAROUZE S.N. and CASANOVA J.: The efficacy of lateral atlanto-axial intraarticular steroid injection in the management of cervicogenic headache (abstract). Anesthesiology, 101: A1005, 2004.

9- NAROUZE S.N., CASANOVA J. and MEKHAIL N.: The longitudinal effectiveness of lateral atlanto-axial intra-articular steroid injection in the management of cervicogenic headache. Pain Med., 8: 184-8, 2007.

10- HETTA D.F., ELAWAMY A.M., HASSANEIN M.M., ALJOHI A.S., HASAN R.A., MOHAMMED N.A.A. and SEIFELDEIN G.S.: Efficacy of Atlantoaxial Joint Glucocorticoid Injection in Patients with Rheumatoid Arthritis: A Randomized Trial. Pain Physician., Jul., 22 (4): E295E302, 2019.

11- ALETAHA D., NEOGI T., SILMAN A., FUNOVITS J., FELSON D.T., et al.: Rheumatoid arthritis classification criteria: An America College of Rhuematology/European League Against Rheumatism collaborative initiative. Ann. Rheum. Dis., 69: 1580-8. [PubMed], 2010.

12-BUYSSE DANIEL J., REYNOLDS CHARLES F., MONK TIMOTHY H., BERMAN SUSAN R. and KUPFER DAV ID J.: "The Pittsburgh sleep quality index: A new instrument for psychiatric practice and research". Psychiatry Research. May, 28 (2): 193-213. doi:10.1016/0165-1781 (89)90047-4, 1989.

13-NAROUZE S.: Natlanto-axial and Atlanto-Occipital Joints Injection in the Treatment of Headaches and Neck Pain. In: Deer T. et al. (eds) Comprehensive Treatment of Chronic Pain by Medical, Interventional, and Integrative Approaches. Springer, New York, NY, pp. 87-91. DOIhttps://doi.org/10.1007/978-1-4939-1824-9_8, 2013.

14- WASSERMAN B.R., MOSKOVICH R. and RAZI A.E.: Rheumatoid arthritis of the cervical spine-clinical considerations. Bulletin of the NYU Hospital for Joint Diseases, 69 (2): 136-48, 2011.

15- KRAUSS W.E., BLEDSOE J.M., CLARKE M.J., NOTT MEIER E.W. and PICHELMANN M.A.: Rheumatoid arthritis of the craniovertebral junction. Neurosurgery, 66 (3): A83-A95. doi: 10.1227/01. NEU.0000365854. 13997.B0, 2010.

16- JOAQUIM A.F. and APPENZELLER S.: Cervical spine involvement in rheumatoid arthritis-a systematic review. Autoimmunity Reviews, 13 (12): 1195-202. doi: 10.1016/j.autrev.2014.08.014, 2014.

17- MATTESON E.L.: Cervical spine disease in rheumatoid arthritis: How common a finding? How uncommon a problem? Arthritis \& Rheumatism, 48 (7): 1775-8. doi: 10.1002/art.11085, 2003.

18- RAJANGAM K. and THOMAS I.M.: Frequency of cervical spine involvement in rheumatoid arthritis. J. Indian Med. Assoc., Apr. 93 (4): 138-9, 137. 7, 1995. 
19- LUYSTER F.S., CHASENS E.R., WASKO M.C. and DUNBAR-JACOB J.: Sleep quality and functional disability in patients with rheumatoid arthritis. J. Clin. Sleep Med., 7: 49-55, 2011.

20- MALLORY G.W., HALASZ S.R. and CLARKE M.J. Advances in the treatment of cervical rheumatoid: Less surgery and less morbidity. World Journal of Orthopaedics. 5 (3): 292-303. doi: 10.5312/wjo.v5.i3.292, 2014.
21- AIUDI C., MICHAEL W., SANDERS R., WATSON J., MOESCHLER S., GAZELKA H., HOELZER B., ELDRIGE J., QU W. and LAMER T.: Outcomes of C1-2 joint injections. Journal of Pain Research, 10: 2263-9, 2017.

22- NAROUZE S.N., CASANOVA J. and MEKHAIL N. The longitudinal effectiveness of lateral atlanto-axial intra-articular steroid injection in the management of cervicogenic headache. Pain Med., 8: 184-8, 2007.

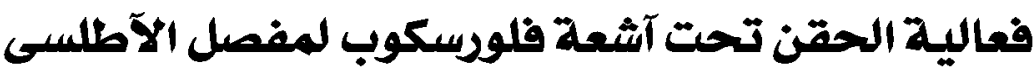

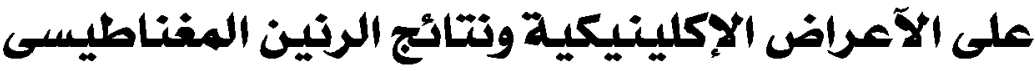

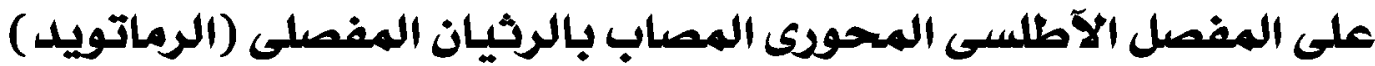

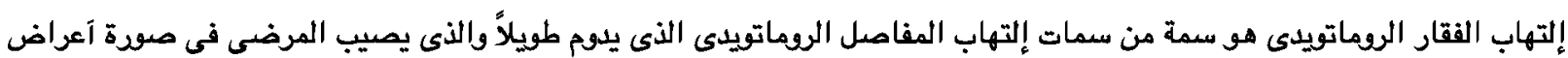

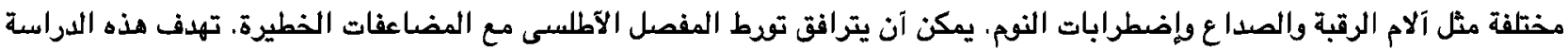

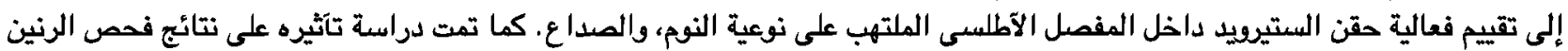
المفناطيسى على مرضى إلتهاب المفاصل الآطلسى الروماتويدى الملتهية.

شملت الدراسة على .7 مريض يعانوا من إلتهاب المفصل الآطلسى. وتم تقسيمه إلى مجموعتين المجموعة المجيم (مجموعة الحقن وعددها

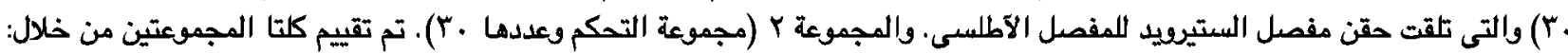

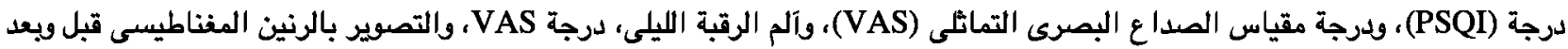

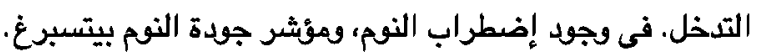

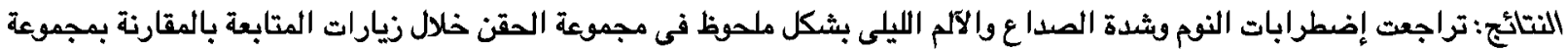

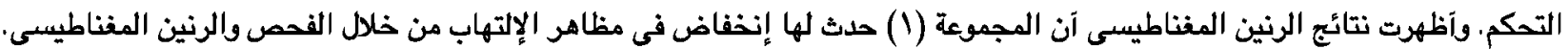
الخلاصة: تشير نتائج الدراسة إلى وجود تآثير واضح ومضاد للإلتهاب لحقن الستيرويد داخل المفصل الآطلسى الملتهب وذلك إستاداً على الآعراض الإكلينيكية ونتائج الرنين المغناطيسى. 